\title{
ANATOMIC VARIABILITY OF BRANCHES OF ILIAC AND FEMORAL ARTERIES IN HUMAN FETUSES
}

\author{
Tatiana V. KHMARA ${ }^{1 凶}$, Pavlina V. HRYHORIEVA ${ }^{1}$, Alla V. VASYLCHYSHYNA ${ }^{1}$, \\ Alexander V. TSYHYKALO ${ }^{1}$, Igor I. ZAMORSKII ${ }^{1}$, Mariana A. RYZNYCHUK ${ }^{1}$
}

${ }^{1}$ Higher State Educational Institution of Ukraine „Bukovinian State Medical University“, Chernivtsi, Ukraine

Received 04 Jan 2019, Accepted 18 Febr 2019

hitps://doi.org/10.31688/ABMU.2019.54.1.11

\section{Abstract}

Introduction. The anatomy of the gluteal and anterior femoral regions is characterized by considerable age and individual variability of the muscles and neurovascular formations, which is a rather common cause of complications during surgical interventions.

Objective. The study aimed at determining the age and individual anatomical variability of the parietal branches of the internal iliac artery and the branches of the external iliac and femoral arteries during the fetal period of human ontogenesis.

Materials and methods. The study included 80 specimens of fetuses, aged 4-10 months, of 81.0-375.0 $\mathrm{mm}$ of crown-rump length (CRL), without external signs of anatomical impairments or developmental malformations.

Results. The branches of the iliolumbar artery anastomosis with the deep circumflex iliac artery and obturator artery; the lateral sacral arteries anastomosis with the branches of the median sacral artery. The branches of the right and left superior gluteal arteries (SGA) anastomosis at different frequencies with the internal pudendal artery, the inferior gluteal artery (IGA), the deep circumflex iliac artery, the lateral femoral

\section{Résumé}

La variabilité anatomique des branches artérielles iliaque et fémorale chez les foetus humains

Introduction. L'anatomie des régions fémorale et iliaque antérieure est caractérisée par un âge considérable et une variabilité individuelle des muscles et des nerfs vasculaires, ce qui est une cause assez fréquente de complications lors des interventions chirurgicales.

Le but de l'étude. Déterminer l'âge et la variabilité anatomique individuelle des branches pariétales de l'artère iliaque interne et des branches des artères iliaque et fémorale externes au cours de la période foetale de l'ontogenèse humaine.

Matériaux et méthodes. 80 préparations de foetus âgés de 4 à 10 mois et d'une longueur pariéto-coccylique (LPC) de 81,0 à 375,0 mm ont été étudiées sans signes externes d'anomalies anatomiques ou de développement.

Résultats. Les branches de l'artère lombaire sont anastomosées avec une artère de flexion profonde de l'os iliaque et une artère verrouillable; les artères sacrales latèrales sont anastomosées avec des branches de l'artère sacrale interne. Les branches des artères sacrées 
circumflex artery (LFCA), the fourth lumbar artery and the obturator artery. The inferior epigastric artery anastomoses with the inferior posterior intercostal arteries, the lumbar arteries, and the superior epigastric artery. The latter also anastomoses with the branches of the superficial epigastric artery. The branches of the right and left medial femoral circumflex artery (MFCA) with different frequency form anastomoses with the obturator artery, IGA and SGA, the internal pudendal artery, LFCA and the first perforating artery. Also. the variants of the topography of the accompanying artery of the sciatic nerve in human fetuses were indicated.

Conclusions. 4-10-month-old fetuses are characterized by the age and individual anatomical variability of the arteries of the pelvic and femoral walls.

Keywords: fetal period, arterial branching, gluteal and anterior femoral region.

\section{INTRODUCTION}

The anatomy of the gluteal and anterior femoral regions is characterized by considerable age and individual variability of the muscles and neurovascular formations, which is a rather common cause of complications during surgical interventions performed within the range of the supra- and infrapiriform foramina, the obturator canal, the femoral ring, the femoral triangle and the adductor canal. The data dealing with previously unknown variants of topography and branching of the arteries and nerves of the gluteal and anterior femoral regions into clinical practice provides the successful performing of diagnostic and therapeutic manipulations on the neurovascular formations. Awareness of age and individual anatomical variability of main arteries determines the success of planned and urgent surgical interventions, as well as some diagnostic procedures. The variants of topography and branching of the system of the iliac and femoral arteries, their age and individual anatomical variability deserve special attention among the topical problems of fetal anatomy.

Neglecting the data on certain topographic variants of the vessels of the pelvis and the lower extremities can cause iatrogenic damage to the arteries, and as a consequence - the occurrence of bleeding and ischemia of the distal parts of the extremity, and necrosis development. As some authors ${ }^{1}$ emphasize, it is possible to avoid iatrogenic vessel damage by a proper knowledge of the anatomical and topographic peculiarities in the area of surgery, performing operations carefully, and by preferring noninvasive methods of diagnosis. Arterial occlusive diseases of the lower supérieures droite et gauche (ASS) sont anastomosées avec des fréquences variables avec l'artère thoracique interne, l'artère fossale inférieure (AFI), l'artère de flexion profonde de l'os iliaque, l'artère oblongue latérale de la cuisse (AOAC), la quatrième artère lombaire et l'artère chordale. L'artère abdominale inférieure est anesthésiée avec les artères inférieures du cerveau postérieur, les artères lombaires et l'artère suprapubienne supérieure. Cette dernière est ègalement une anastomose des branches de l'artère suprapéritonèale superficielle. Sont également incluses des variantes de la topographie de l'artère accompagnant le nerf sciatique chez le foetus humain.

Conclusion. Chez les foetus âgés de 4 à 10 mois, l'âge et la variabilité anatomique individuelle des artères des parois du bassin et des cuisses ont été détectés.

Mots-clés: période foetale, ramification artérielle, zone fémorale postérieure et antérieure.

extremities remain an important issue of modern health care ${ }^{2}$. In recent years, much attention has been paid to selective medication therapy, which is carried out by catheterization of vessels that supply blood to a specific area, which allows the administration of high toxicity drugs (cytostatic, antibiotics) directly to the pathological site. This method of treatment allows a significant decrease of drugs doses and a directly supply of the damaged tissue, avoiding the liver, spleen and lymph nodes. Surgeons, traumatologists, and oncologists must take into account the variant peculiarities of the structure of the main neurovascular bundle within the area of the adductor canal and the femoral triangle, in order to prevent postoperative complications while performing surgical procedures on the lower extremity ${ }^{3.5}$.

The arterial bleeding from the internal iliac artery may lead to serious and sometimes fatal consequences. Some authors ${ }^{6,7}$ note the variability of the topography of the obturator artery. Other research$\mathrm{ers}^{7}$ observed the obturator artery originating from the anterior trunk of the internal iliac artery in 79\% of cases. In 19\% of observations, the obturator artery was branching from the external iliac artery as an independent branch or was arising along with the inferior epigastric artery. In $2 \%$ of cases, the double origin of the obturator artery from the internal and external iliac arteries was detected. The iliac artery pool is one of the main objects of surgical interventions, due to frequent involvement of the external iliac arteries in the pathological process.

The endovascular embolization of the major trunks of vessels is the main method of treatment of arterial aneurysms ${ }^{8}$. Data dealing with the variant 
anatomy of branching of the main and collateral pathway of the deep femoral artery are contradictory9.

The persistent sciatic artery that replaces the femoral artery is an anomaly difficult to diagnose, leading to ischemia of the lower extremity ${ }^{7,10-13}$. The resources contain data of topographic variants of the accompanying artery of sciatic nerve ${ }^{14-17}$. Clinical observation of a patient with abnormal course of iliac and femoral arteries is reported by Tsygankov et $\mathrm{a}^{13}$. The anomaly did not allow to perform the embolization of afferent arteries of the lower leg in case of arteriovenous angiodysplasia. The authors noted the necessity of using computed angiography in the preoperative stage. Aristarkhov ${ }^{18}$ found accompanying artery of sciatic nerve in all (6) investigated preparations of male corpses of mature age. The author noted that the accompanying artery of sciatic nerve grows thinner or disappears at the level of $5.0-9.0 \mathrm{~cm}$ from the point of the sciatic nerve branching into the common peroneal nerve and tibial nerves. Therefore, in order to choose the optimal access to the sciatic nerve, it is advisable to perform an ultrasound imaging of the soft femoral tissues.

Thus, the sources of literature contain fragmentary data concerning the anatomical variability of the system of the iliac and femoral arteries, in different periods of human ontogenesis.

The obJective of THE STUdY was to determine the age and individual anatomical variability of the parietal branches of the internal iliac artery and the branches of the external iliac and femoral arteries, during the fetal period of human ontogenesis.

\section{Materials AND Methods}

The study involved 80 specimens of fetuses aged 4-10 months, of 81.0-375.0 mm of crown-rump length (CRL), without external signs of anatomical impairments or developmental malformations.

Specimens of fetuses weighing over $500 \mathrm{~g}$ were studied in Chernivtsi Regional Communal Medical Facility „Pathologic-anatomical Bureau“, according to the cooperation agreement. In addition, specimens of fetuses from the Museum of the Department of Human Anatomy M.H. Turkevych and the Department of Histology, Cytology and Embryology, Higher State Educational Institution (HSEI) of Ukraine, „Bukovinian State Medical University“, were involved in the research.

The research was carried out in compliance with the basic bioethical provisions of the Council of Europe Convention on Human Rights and Biomedicine (dated 04.04.1997), the Helsinki Declaration of the World Medical Association on the Ethical Principles of Scientific Medical Research with Human Participation (1964-2013), the Order of the Ministry of Health of Ukraine $\mathrm{N}^{\circ} 690$, dated September 23, 2009, and taking into account the methodological recommendations of the Ministry of Health of Ukraine „Procedure of exemption of biological objects from dead persons whose bodies are subject to forensic medical examination and pathological examination for scientific purposes" (2018). The Committee on Biomedical Ethics of the HSEI of Ukraine „Bukovinian State Medical University“ has not revealed any violations of moral and legal norms during the scientific research.

Clarifying the typical and variant anatomy of the branches of the internal and external iliac and femoral arteries, as well as the study of the main intra-and inter-system arterial anastomoses of the pelvis and thigh in the dynamics of the fetal period of human development, require the application of a set of morphological methods. The methodology of morphological research, the rationality of the involved techniques algorithm, the adequacy of their combination and the scientific effectiveness of comparing classical research methods with modern methods of medical diagnostic imaging are of great importance in the process of studying anatomical peculiarities of the iliac and femoral arteries in fetuses of different age groups ${ }^{19-21}$. The implementation of the stages of scientific research in a rational sequence ensures not only the high representativeness and statistical value of the obtained results, but also the rational use of the material ${ }^{22}$.

It is well known that the reliability of the obtained results of the research depends on the correct selection and successful combination of methodical and methodological means. Therefore, the most informative approaches were used as methodical ones. To find out the anatomical variability of the branches of the iliac and femoral arteries, a complex of morphological research methods was used, keeping the following sequence to adhere to scientific methodology: 1) anthropometry; 2) injection of blood vessels; 3) macro-microscopy; 4) superficial staining of the dissected vessels and nerves; 5) computed tomography (CT); 6) three-dimensional computer reconstruction; 7) morphometry; 8) statistical processing of digital data.

First, the corpses of the fetuses were measured, vessels injection was carried out, the specimens were mobilized on a special frame for the shape stability during fixation in 10\% neutral formalin solution for 3 weeks. Specimens were preserved in 5\% formalin solution between stages of the study.

The vessels were injected for further macro-microscopic examination, computed tomography (CT), 
and three-dimensional computer reconstruction. Tubular structures filled with polychrome injection substances are much easier to identify after fixation during dissection and reconstruction. The use of polychrome X-ray contrast agents (a mixture for arteries injection consists of red lead, alcohol and glycerin; a mixture for veins injection consists of barium, glycerol, alcohol and methylene blue), polymers in the composition of injection masses, enables the use of several research methods on one specimen (macro-microscopy, radiography, CT, reconstruction, etc. $)^{22,23}$.

To study the topography of the femoral artery, the cut of the skin was performed along the Ken's line (from the middle of the inguinal ligament to the medial epicondyle of the femoral bone), the subcutaneous fatty cellular tissue, superficial one and of the femoral fascia proper were dissected layer-by-layer and the branches of the femoral artery were isolated.

CT was applied to study the bony walls of the true pelvis, to determine the terms of the ossification points formation in the coxal and femoral bones, the size and shape of the pelvis in human fetuses, as well as to determine the layered structure and skeletontopy of muscles, fascial and cellular spaces of the gluteal and anterior femoral regions, ligaments and neurovascular formations of the pelvis and thigh in the fetal period of ontogenesis. The imaging was performed by a CT scanner Mx8000 IDT (manufacturer Philips Medical Systems (Cleveland) Inc., USA) in the "Center of Traumatology and Orthopedics" Ltd. (Swedish-Ukrainian Clinic „Angelholm“), in accordance with the cooperation agreement.

Three-dimensional computer reconstructions were made from each series of histotopographic sections, to study the spatial structure and topography of the vessels of the gluteal and anterior femoral regions. The suggested methods were used for their three-dimensional reconstruction and morphometry $y^{24-26}$. According to the generally accepted methodology, a paraffin block with a specimen was made, fixed in the microtome holder, and the thickness of consecutive sections $(8 \mu \mathrm{m})$ was set. The digital microphotography equipment was fixed on the tripod, the optical system was focused on the block surface (its optical axis should be perpendicular to the plane of motion of the microtome blade), the images were cropped, and the illumination was simulated. The polychrome injection of blood vessels, performed in the fetus of different ages, greatly facilitates the identification of arteries and veins. The surface of the paraffin block with the specimen was photographed after each working motion of the microtome blade. The micrometric scale was photographed on the first frame in the section plane to scale and calibrate the morphometric module of the computer program for reconstruction and morphometry. Histological specimens were made from separate sections. Three-dimensional computer model of the investigated anatomical structure was produced from a series of digital images obtained by means of specialized software (Virtual Anatomist), morphometry was performed. Three-dimensional CT image was constructed manually, using the Wacom graphical manipulation, a surface rendering. It provides the imaging of the anatomical structure with a certain color at each section, allowing to clearly represent their shape, arrangement, relative dimensions, etc. In addition, it makes it possible to accurately perform morphometry - to determine the sizes, angles, area, and volume.

Volume rendering - one of the types of three-dimensional computer reconstruction - was applied during the study of a series of histological sections of the contrasted vascular system of the specimens of the gluteal and femoral regions. To do this, there is no need to manually segment the structures being studied. It should be noted that this is possible only when the image of the sections contains one-two colors, that is, there is a gradient that allows a computer program to accurately determine the boundaries of anatomical structures. In this case, this is the boundary between contrast in the vessel and adjacent tissues without contrast. This method of three-dimensional reconstruction allows to study the shape of contrasted tubular structures and measure their volume. Three-dimensional reconstruction model of the investigated structures was made from a series of digital images with the help of the corresponding software, and morphometry was performed. Morphometry of anatomical structures on their three-dimensional reconstruction models was carried out using computer software for reconstruction and morphometry.

RadiAnt DICOM Viewer software (Poland) was used for three-dimensional reconstruction of the investigated structures by the series of computer-tomographic sections of contrasted specimens, as well as for their morphometry.

Consequently, the suggested and tested complex of methods of morphological study of blood supply to the gluteal and anterior femoral regions in the fetal period of human ontogenesis ensures the standard obtaining of data on the topography of the branches of the internal and external iliac and femoral arteries.

\section{Results}

In the examined fetuses, the abdominal aorta is branching into the right and left common iliac arteries at the level of the lower edge of the III or at the level of the upper edge of the IV lumbar vertebra, as a rule, somewhat to the left from the anterior median 
line. At the point of the aorta bifurcation, the common iliac arteries diverge at an acute angle, go down and laterally to the region of the sacroiliac joint, at the level of which each common iliac artery divides into internal and external iliac arteries. The femoral artery is the continuation of the external iliac artery (Fig. 1). The internal iliac artery goes to a true pelvis, reaches the upper edge of the sciatic foramen and is divided into the posterior and the anterior trunks. All branches, except the iliolumbar artery, the lateral sacral arteries and the superior gluteal artery (SGA), arise from its anterior trunk.

The iliolumbar artery originates from the posterior trunk of the internal iliac artery. At the medial edge of the psoas major muscle, the iliolumbar artery is divided into the lumbar and iliac branches. The latter is branching into the superficial and deep branches. Its superficial branch passes along the iliac crest and anastomoses with the deep circumflex iliac artery from the external iliac artery, forming an arch (Fig. 2), the branches of which supply with blood the iliac muscle and the inferior portions of the muscles of the anterior abdominal wall. The deep branch gives off $2-3$ thin branches to the iliac bone and anastomoses with the obturator artery. The lumbar branch of the iliolumbar artery corresponds to the dorsal branch of the lumbar arteries, passes along the dorsal one and gives off the spinal branch. The lumbar branch supplies with blood psoas major and minor muscles, quadratus lumborum muscle and the posterior regions of the transverse abdominal muscle.

The lateral sacral arteries pass medially along the anterior surface of the sacrum, more medially than the anterior sacral openings and give off the medial and lateral branches. Medial branches, $2-6$ in number, anastomose with the branches of the median sacral artery and form a network. The lateral branches, 2-4 in number, enter the sacral canal through the pelvic sacral openings and give off the spinal branches. Further, the lateral branches pass through the posterior sacral openings, supply with blood sacral bone, the skin of the sacral region, the sacroiliac joint, the piriformis muscle, the inferior portions of the deep dorsal muscles.

The obturator artery originates from the anterior trunk of the internal iliac artery, goes to the obturator foramen, where it gives off the pubic branch. The obturator artery arises from the pelvic cavity through the obturator canal, in which it is divided into the anterior and posterior branches. The obturator artery gives off the acetabular branch to the acetabular joint.

SGA is the largest branch of the internal iliac artery, the continuation of its posterior trunk. SGA, after arising from the pelvic cavity through a supra

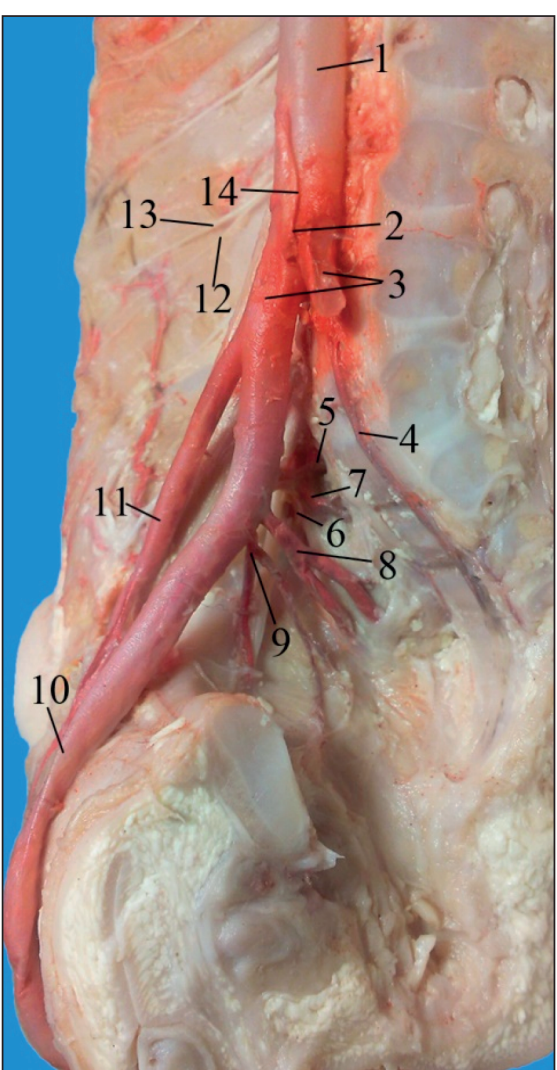

Fig. 1. Vessels and nerves of the pelvis of the fetus, $260.0 \mathrm{~mm}$ of CRL. Macro specimen. Magnification $1.8^{\mathrm{x}}$ :

1 - abdominal aorta; 2 - abdominal aorta bifurcation;

3 - common iliac arteries; 4 - median sacral artery;

5 - iliolumbar artery; 6 - iliac branch of iliolumbar artery;

7 - lumber branch of iliolumbar artery; 8 -inferior epigastric artery; 9 - external pudendal artery; 10 - femoral artery; 11 - internal iliac artery; 12 - ilioinguinal nerve; 13 - iliohypogastric nerve; 14 - inferior mesenteric artery.

piriform foramen $(86.3 \%$ of cases on the right and $88.8 \%$ of observations on the left), is divided into the superficial and deep branches. In two cases (the fetuses of 190.0 and $245.0 \mathrm{~mm}$ of CRL), the division of the left SGA on the final branches occurred in the pelvic cavity. The deep branch of the SGA anastomoses with the corresponding internal pudendal artery on the right in $20 \%$ of the observations and on the left in $28.8 \%$ of the cases. The deep branch of the SGA, in its turn, branches out to the superior and inferior branches.

The superficial branch of SGA anastomoses with the inferior gluteal artery (IGA) in $78.8 \%$ of the observations on the right and in $83.8 \%$ of the cases on the left. The superficial branch originates from the superior deep branch of the SGA in 5\% of cases on the right and in $8.8 \%$ of cases on the left. Anastomoses of the superficial branch of the left SGA with the internal pudendal artery were also found in $5 \%$ of cases on the right and in $7.5 \%$ of cases on the 


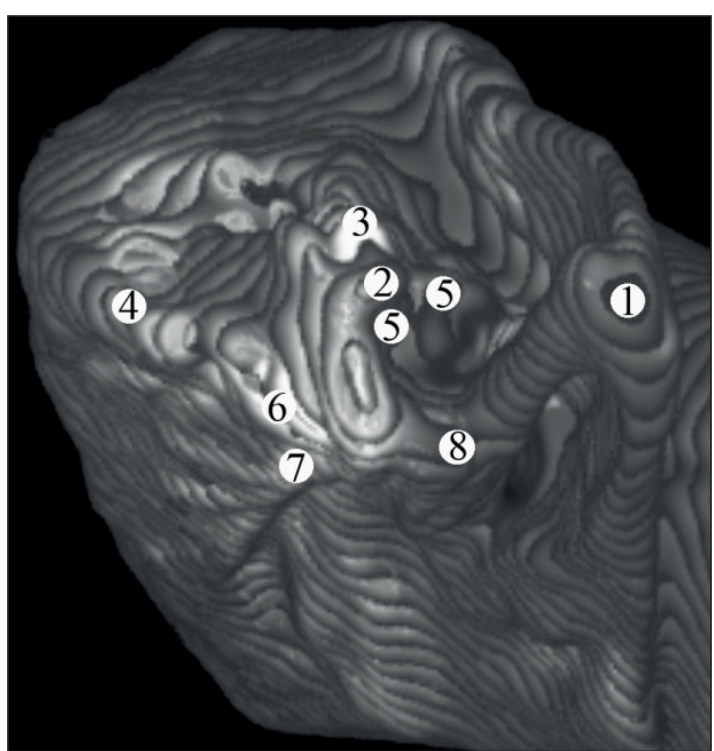

Fig. 2. Computed tomography of arteries of the left gluteal region in fetus of $235.0 \mathrm{~mm}$ of CRL. Front-medial projection. Magnification 2.5 :

1 - internal iliac artery; 2 - superior gluteal artery;

3 - iliolumbar artery; 4 - deep circumflex iliac artery;

5 - lateral sacral arteries; 6 - obturator artery;

7 - inferior gluteal artery; 8 - internal pudendal artery.

left. The superior deep branch of the SGA was found in $13.8 \%$ of cases on the right and in $17.5 \%$ - on the left. Its anastomoses with the deep circumflex iliac artery (15\% of observations on the right and $18.8 \%$ of cases on the left) and with the IGA (42.5\% of cases on the right and $46.3 \%$ of observations on the left) were found. Branching of the right SGA from the internal iliac artery as a common trunk with the IGA was observed in the fetus of $280.0 \mathrm{~mm}$ of CRL.

The muscular branches of the SGA, $2-7$ in number, are anastomosed with the deep circumflex iliac artery $(18.8 \%$ of cases on the right and $31.3 \%$ on the left) and with the IGA (26.3\% of observations on the right and $33.8 \%$ on the left).

In rare cases, the right (fetus of $305.0 \mathrm{~mm}$ of CRL) and the left SGA (fetuses of 245.0 and 280.0 $\mathrm{mm}$ of $\mathrm{CRL}$ ) are anastomosed with the corresponding lateral femoral circumflex artery (LFCA); with right (fetuses of 225.0 and $260.0 \mathrm{~mm}$ of CRL) and left (fetuses of 260.0 and $275.0 \mathrm{~mm}$ of CRL) fourth lumbar arteries.

In two observations (2.5\%) (fetuses of 200.0 and $330.0 \mathrm{~mm}$ of CRL) the right SGA and in five cases (6.3\%) (fetuses of 235.0, 250.0, 275.0, 305.0 and $350.0 \mathrm{~mm}$ of CRL) the left SGA anastomose with the corresponding obturator artery (Fig. 3).

IGA $(78.8 \%$ of cases on the right and $86.3 \%$ of observations on the left) anastomoses with the superficial branch of SGA and with the superior deep

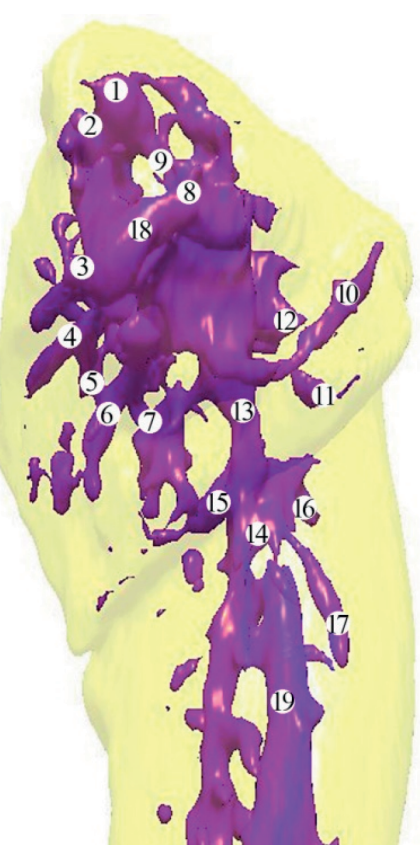

Fig. 3. Computer three-dimensional reconstruction of structures of the left lower extremity in the fetus of $235.0 \mathrm{~mm}$ of CRL. Arteries injected with the solution on the basis of red lead.

Front-medial projection. Magnification $1.8^{\mathrm{x}}$ :

1 - common iliac artery; 2 - internal iliac artery;

3 - superior gluteal artery; 4 - obturator artery;

5 - inferior gluteal artery; 6 - internal pudendal artery;

7 - inferior rectal artery; 8 - iliolumbar artery;

9 - external iliac artery; 10 - inferior epigastric artery;

11 - pubic branch; 12 - deep circumflex iliac artery;

13 - femoral artery; 14 - deep femoral artery;

15 - lateral femoral circumflex artery; 16 - medial femoral circumflex artery; 17 - descending branch;

18 - coxal bone; 19 - femoral bone.

branch of SGA $(42.5 \%$ of cases on the right and $46.3 \%$ of observations on the left), that was mentioned above. IGA also anastomoses with the obturator artery (in $18.8 \%$ of cases on the right and in $16.3 \%$ of observations on the left) (Fig. 4). In 23.8\% of cases (19 specimens) the right IGA and in $26.3 \%$ of observations (21 specimens) the left IGA are anastomosed with the corresponding medial femoral circumflex arteries (MFCA).

In human fetuses, the accompanying artery of the sciatic nerve, which is the branch of the gluteal region of the IGA, is usually placed on the posterior or posterior-medial surface of the nerve, supplying it with blood. In rare cases (fetuses of 260.0 and 275.0 $\mathrm{mm}$ of $\mathrm{CRL}$ ), the tendency of the transition of the accompanying artery of the sciatic nerve to its lateral surface was noted (Fig. 5). Three arteries diverged from the right IGA to the sciatic nerve, at different angles in the fetus of $215.0 \mathrm{~mm}$ of CRL: superior, middle and inferior, and three branches: two medial 
and lateral ones in the fetus of $315.0 \mathrm{~mm}$ of CRL. The gluteal region of the IGA, and in rare cases the accompanying artery of the sciatic nerve, are involved in the blood supply to gluteus maximus and gluteus medium, piriformis and gemelli muscles, quadratus femoris muscle, semimembranosus and semitendinosus muscles, long head of the biceps femoris muscle.

The internal pudendal artery, as a rule, arises from the anterior trunk of the internal iliac artery independently. In rare cases (6 on the right and 4 on the left), there was revealed a common origin of the internal pudendal artery with IGA as a common trunk from the anterior trunk of the corresponding internal iliac artery. A common origin of the left internal pudendal artery, along with the left SGA from the left internal iliac artery was observed in one fetus. The internal pudendal artery is characterized by a trunk-loose pattern of structure.

The inferior epigastric artery originates from the anterior surface of the external iliac artery before its entrance in the vascular lacuna. The artery is directed craniomedially along the posterior surface of the anterior abdominal wall between the transverse fascia in the front and the parietal peritoneum from behind. The inferior epigastric artery penetrates the rectus abdominis muscle sheath, locating between the latter and the posterior wall of its sheath and by means of its branches it anastomoses with the superior epigastric artery (the branch of the internal thoracic artery), with the terminal branches of the inferior four or five posterior intercostal and lumbar arteries. The deep circumflex iliac artery originates from the lateral wall of the external iliac artery, it runs parallel to the inguinal ligament towards the iliac crest, where it gives off the branches to the muscles of the anterior-lateral wall of the abdomen and the iliac muscle. Its terminal branches anastomose with the iliac branch of the iliolumbar artery from the internal iliac artery.

The femoral artery is a continuation of the external iliac artery and originates under the inguinal ligament in the vascular lacuna. Medially to femoral artery there is the femoral vein, along with which it passes through the femoral triangle, first in the iliopectineal sulcus, and then in the anterior femoral sulcus (Fig. 6). At the edge of the middle and lower third of the thigh, the femoral artery passes through the superior foramen of the adductor canal. The femoral vein and subcutaneous nerve pass through the adductor canal together with the femoral artery. The superficial epigastric artery originates from the anterior wall of the femoral artery below the inguinal ligament (Fig. 7). The artery then permeates the superficial lamina of the fascia lata in the region of the saphenous opening, goes up and medially, passes to

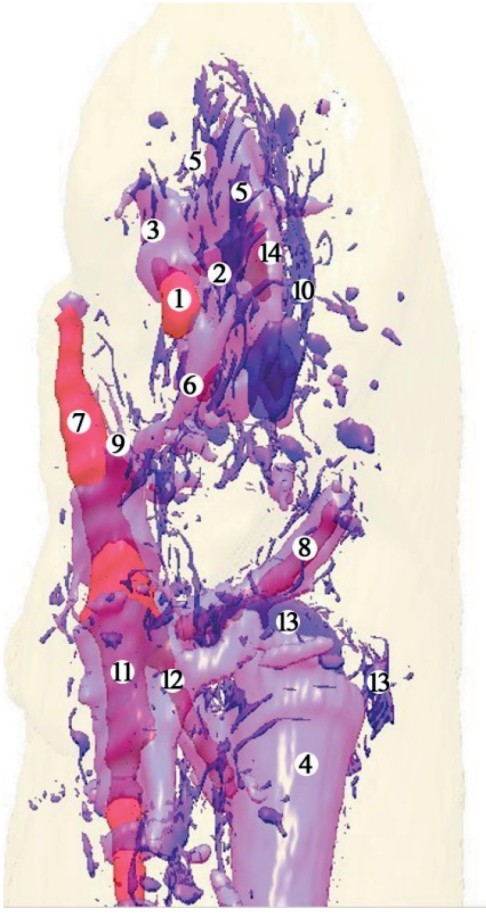

Fig. 4. Computer three-dimensional reconstruction of structures of the left lower extremity in the fetus of $290.0 \mathrm{~mm}$ of CRL. Poly contrast injection

of blood vessels. Front projection. Magnification 2.6

1 - inferior gluteal artery; 2 - obturator artery; 3 - superior gluteal artery; 4 - femoral bone; 5 - iliolumbar veins; 6 - internal pudendal vessels; 7 - external iliac artery; 8 - inferior epigastric vessels; 9 - deep circumflex iliac artery; 10 - deep circumflex iliac vein; 11 - femoral artery; 12 - external pudendal artery; 13 - lateral femoral circumflex veins; 14 - coxal bone.

the anterior abdominal wall, where it is located subcutaneously, and reaches the navel area. The branches of the superficial epigastric artery are anastomosed with the branches of the superior epigastric artery.

The superficial circumflex iliac artery mainly arises from the external wall of the femoral artery or, in three cases, from the superficial epigastric artery, goes along the inguinal ligament to the superior anterior iliac spine.

The pudendal arteries, $2-3$ in number, go medially, circumflexing the femoral vein. One of the branches goes upwards, supplying blood to the skin of the suprapubic region, others go to the scrotum or pudendal lips (depending on the sex) called the anterior scrotal, or the anterior labial branches.

The inguinal branches, usually $2-4$ in number, penetrate the fascia lata in the region of the cribriform fascia, supplying blood to the skin, to the superficial and deep inguinal lymph nodes.

The deep femoral artery (DFA) is the largest branch of the femoral artery and originates from 


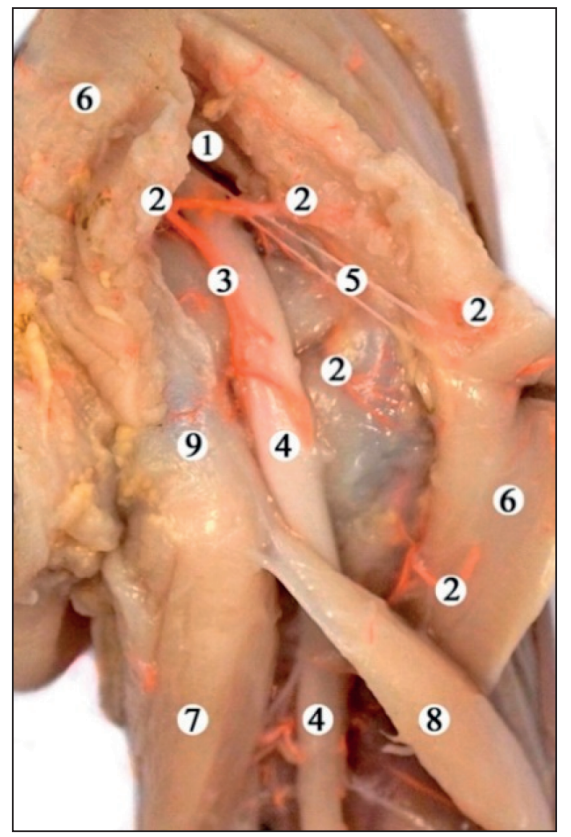

Fig. 5. Right gluteal region of the fetus of $260.0 \mathrm{~mm}$ of CRL. Macro specimen. Magnification 2.1 ${ }^{x}$ :

1 - infra-piriform foramen; 2 - branches of the inferior gluteal artery; 3 - accompanying artery of sciatic nerve; 4 - sciatic nerve; 5 - branches of the inferior sciatic nerve; 6 - gluteus maximus; 7 - semitendinosus muscle; 8 - long head of the biceps femoris muscle; 9 - tuber ischiadicum.

its posterior wall 7.0-8.5 $\mathrm{mm}$ below the inguinal ligament. The DFA is located on the iliopsoas and pectineus muscle; first, it goes to the exterior, and then caudally, behind the femoral artery. Further, the DFA passes between the vastus medialis muscle of the thigh and the adductor muscles and terminates within the lower third of the thigh between the adductor magnus and adductor longus muscles in the form of the third perforating artery. From the DFA the MFCA arises, which is located in the fascial sheath, formed by a rather thin own femoral fascia, passes in a thin layer of loose cellular tissue, goes medially and upwards, gives off the superficial branch, which supplies blood to the adductor longus and brevis muscles, pectineus, gracilis and external obturator muscles. A deep branch, located between the external obturator muscle and the quadratus femoris muscle, is the continuation of MFCA. The acetabular branch goes to the acetabular joint, where it is anastomosed with the same named branch of the obturator artery $(86.3 \%$ of cases on the right and $88.8 \%$ on the left). MFCA also anastomoses with the inferior gluteal artery $(73.8 \%$ on the right and $65 \%$ on the left); with the inferior branch from the deep branch of the superior gluteal artery $(36.3 \%$ on the right and $27.5 \%$ on the left); with the internal pudendal artery $(41.3 \%$ on the right and $47.5 \%$ on the

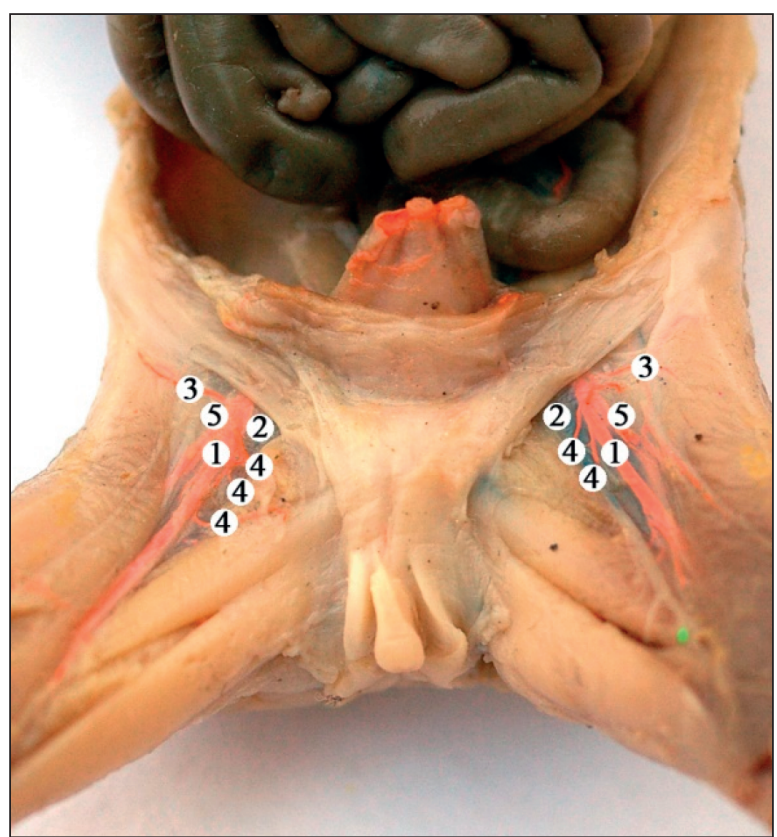

Fig. 6. Vessels of the right and left anterior femoral regions within the upper third of the female fetus of $165.0 \mathrm{~mm}$ of CRL. Macro specimen. Magnification 2.6

1 - femoral artery; 2 - femoral vein; 3 - superficial circumflex iliac artery; 4 - external pudendal arteries; 5 - deep femoral artery.

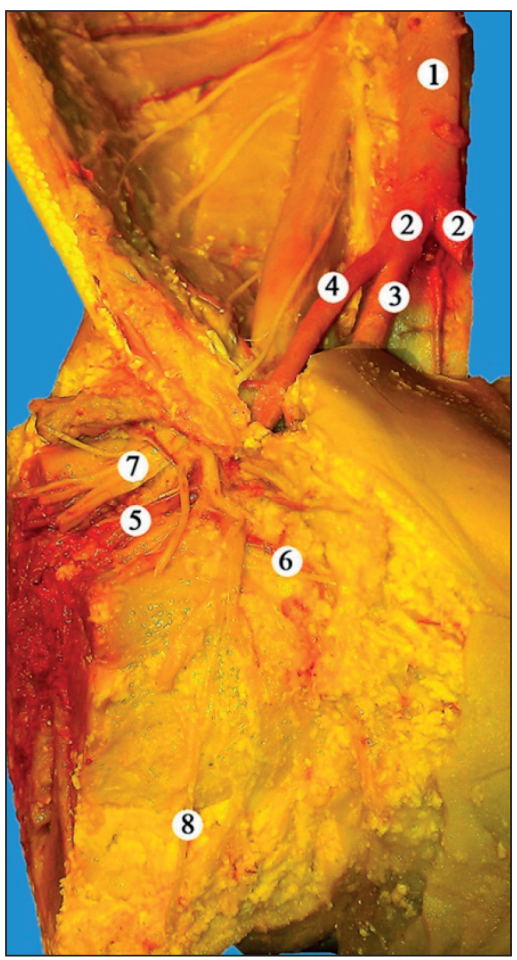

Fig. 7. Vessels and nerves of the right anterior femoral region within the upper third of the fetus of $235.0 \mathrm{~mm}$ of CRL. Macro specimen. Magnification 2.4

1 - abdominal aorta; 2 - common iliac arteries; 3 - internal iliac artery; 4 - external iliac artery; 5 - femoral artery; 6 - superficial epigastric artery; 7 - femoral nerve; 8 - saphenous nerve. 
left); with the first perforating artery on the right in $13.8 \%$ of observations. The ascending and descending branches originate either directly from the MFCA $(83.8 \%)$, or from its deep branch. Within the posterior muscular-fascial femoral compartment, behind the femur, MFCA anastomoses with LFCA, forming the arterial circle. LFCA originates from DFA predominantly (82.5\%) slightly lower than MFCA, passing in the fascial sheath, formed by femoral own fascia, laterally in front of the iliolumbar muscle, behind the sartorius muscle and the rectus femoris muscle and is branched into the ascending, descending and transverse branches at the level of the greater trochanter of the femur. LFCA branches supply blood to the quadriceps femoris muscle, the tensor fasciae lata muscle and the gluteus medium muscle. Along the pathway LFCA anastomoses with the internal pudendal artery $(73.8 \%$ on the right and $67.5 \%$ on the left); with the obturator artery $(61.3 \%$ on the right and $71.3 \%$ on the left); with the inferior branch from the deep branch of the superior gluteal artery $(36.3 \%$ on the right and $47.5 \%$ on the left); with the inferior gluteal artery $(43.8 \%$ on the right and $48.8 \%$ on the left); with the first perforating artery $(32.5 \%$ on the right and $26.3 \%$ on the left) (Fig. 8). Perforating arteries, $2-3$ in number, arise from the DFA at different levels, thus the first one - at the level of the inferior edge of the pectineus muscle, the second - at the inferior edge of the adductor brevis muscle, the third one - below the adductor longus muscle. The perforating arteries pass through the adductor muscles in the point of their attachment to the femoral bone and supply blood to the adductor muscles, semimembranosus and semitendinosus muscles, biceps femoris muscle and the skin of the posterior surface of the thigh. The second and third perforating arteries give off the nutrient arteries of the femur.

\section{Discussion}

It is generally known that the intensity of collateral blood circulation depends not only on the functional state of vessels, primarily the tone of their walls, but also on the topographic and anatomical peculiarities of the vessels: the size of the diameter, the angle at which the branches originate from the main vascular trunk, the number of lateral branches, the type of branching, the number of anastomoses with adjacent vessels. Data on intra-system and intersystem arterial anastomoses of the pelvic walls and lower extremities are of great practical importance. The branches of the external and internal iliac arteries form anastomoses with the system of the subclavian artery, the branches of the abdominal aorta, and their branches also anastomose with each other.

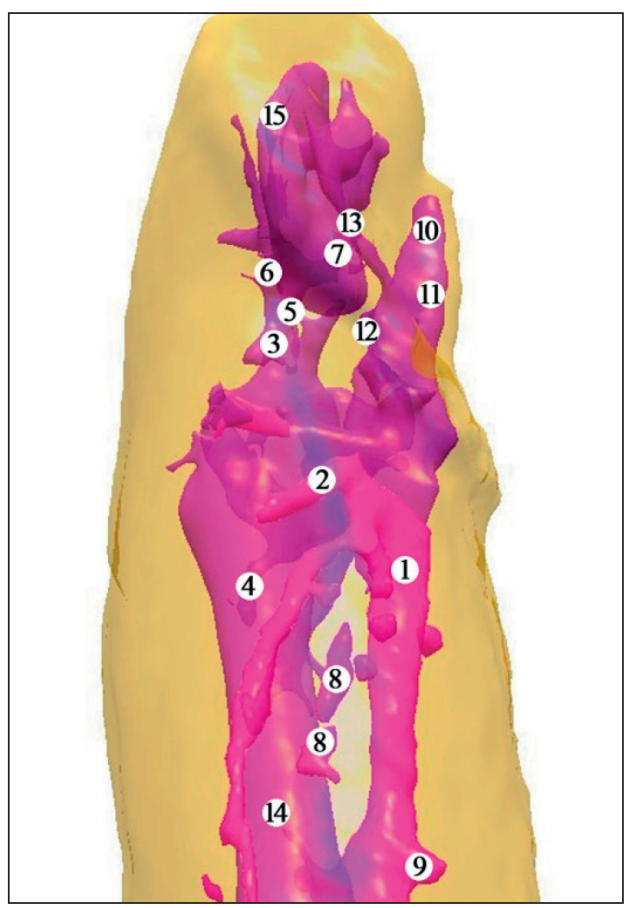

Fig. 8. Computer three-dimensional reconstruction of structures of the right lower extremity in the fetus of $265.0 \mathrm{~mm}$ of CRL. Arteries injected with the solution on the basis of red lead. Front projection. Magnification 2.2

1 - femoral artery; 2 - lateral femoral circumflex artery; 3 - ascending branch; 4 - descending branch; 5 - obturator artery; 6 -inferior gluteal artery; 7 - superior gluteal artery; 8 - perforating arteries; 9 - descending genicular artery; 10 - common iliac artery; 11 - internal iliac artery; 12 - external iliac artery; 13 - iliolumbar artery;

14 - femoral bone; 15 - coxal bone.

The intersystem anastomoses can be collateral way of blood flow to the lower extremity in case of occlusion of the iliac arteries or abdominal aorta. The presence of intersystem anastomoses, in particular between the IGA and LFCA, the obturator artery and MFCA, provides the restoration of collateral circulation in case of femoral artery bandaging.

The research, dealing with the fetal anatomy of the parietal branches of the internal and external iliac and femoral arteries, resulted in identifying some intra-system and intersystem arterial anastomoses. The branches of the iliolumbar artery are anastomosed with the deep circumflex iliac artery and the obturator artery; the lateral sacral arteries are anastomosed with the branches of the median sacral artery. The branches of the right and left SGA are anastomosed with varying frequency with the internal pudendal artery, IGA, the deep circumflex iliac artery, LFCA, the fourth lumbar artery, and the obturator artery. The branches of the right and left IGA form anastomoses with different frequency with SGA, the obturator artery, MFCA. The inferior 
epigastric artery anastomoses with the inferior posterior intercostal arteries, the lumbar arteries, and the superior epigastric artery. The latter also anastomoses with the branches of the superficial epigastric artery. The branches of the right and left MFCA with different frequency form anastomoses with the obturator artery, IGA and SGA, the internal pudendal artery, LFCA and the first perforating artery. The anastomoses were also found between the branches of LFCA and the internal pudendal artery, the obturator artery, SGA and IGA, the first perforating artery with different frequency on the right and on the left. The obtained data on anastomoses between the arteries of the pelvis and lower extremities are to some extent consistent with the studies of Shkvarko and Kuzmenko ${ }^{27}$. The variants of topography of the parietal branches of the internal iliac artery and branches of the external iliac and femoral arteries revealed in the human fetuses and the data on their intra- and intersystem anastomoses should be taken into account by the fetal and neonatal surgeons during operative interventions.

The SGA branching from the internal iliac artery in common trunk with the IGA, which was also described by some authors ${ }^{27}$, was found in one case. In rare cases, a common origin of the internal pudendal artery with the IGA from the anterior trunk of the internal iliac artery was determined; as well as the origin of the superficial circumflex iliac artery from the superficial epigastric artery. The internal pudendal artery, along with the SGA originating from the internal iliac artery, was observed in one fetus.

Only some variants of the topography of the accompanying artery of the sciatic nerve in human fetuses have been highlighted in this article, as they were described in detail in our previous publication ${ }^{14}$.

\section{Conclusions}

4-10-month-old fetuses are characterized by the age and individual anatomical variability of the arteries of the pelvic and femoral walls, which is manifested by topography variants and variability of the number of parietal branches of the internal iliac artery and branches of the external iliac and femoral arteries, with different frequency of formation of intra- and intersystem arterial anastomoses on the right and on the left both in fetuses of different or one age group, and in the same fetus.

The introduction of data on the anatomical variability of the parietal branches of the internal iliac artery, branches of the external iliac and femoral arteries into clinical practice will ensure successful diagnostic and therapeutic manipulations within the gluteal and anterior femoral regions.

\section{Compliance with Ethics Requirements:}

„The authors declare no conflict of interest regarding this article"

"The authors declare that all the procedures and experiments of this study respect the ethical standards in the Helsinki Declaration of 1975, as revised in 2008(5), as well as the national law."

"No funding for this study“

\section{References}

1. Shor NA, Burilov MV. Iatrogenic damage of the main vessels. Klinichna hirurgiya. 2012; 2: 45-47 (in Russian).

2. Yanushko VA, Turlyuk DV, Ladyigin PA, Isachkin DV. Modern approaches to diagnosis and treatment of multilevel lesions of the arteries of the lower extremities below the inguinal fold in the stage of critical ischemia. Novosti hirurgii. 2011;19(6):115-126 (in Russian).

3. Kuzmenko AV, Shkvarko MG. Variant topography of vessels and nerves of the lower third of the thigh, significant for surgical interventions. Akt. voprosyi operat. hir. i klin. anatomii: mater. Mezhdunar. nauch.-prakt. konf., posv. 50-letiyu kafedryi operat. hir. i top. anatomii. Grodno: GrGMU. 2011; 125-129 (in Russian).

4. Zaritskiy AB, Kuzmenko AV, Mamedaliev NA. Variant features of topography of the main neurovascular bundle of the femoral triangle region, significant for femoral artery catheterization. Arhiv klin i eksperim meditsinyi. 2002; 11(2): 17-20 (in Russian).

5. Zhilyaev RA, Zaritskiy AB, Tyazhelov AA. Topographic-anatomical features of the Hunter channel. Ukr morfol almanah. 2007; 5(4): 103-104 (in Russian).

6. Gorustovich OA, Volchkevich DA. Variant anatomy of the obdurate artery. Sb nauch rabot studentov Respubliki Belarus „NIRS 2011“, Minsk. 2012; 326-327 (in Russian).

7. Marincola BC, Napoli A, Anzidei M, et al. Persistence of the sciatic artery: a case report of a combined (complete and incomplete) type causing leg ischemia. Case Rep Vasc Med. 2012;2012(1):5-10.

8. Silberzweig JE. Transcatheter arterial embolization for pelvic fractures may potentially cause a trial of sequela: gluteal necrosis, rectal necrosis, and lower limb paresis. J Trauma. 2009;67(2):416-417.

9. Kuzmenko AV, Shkvarko MG. Variant anatomy of the collateral channel medial and lateral, enveloping the femur of the arteries. Vesennie anatom chteniya: sb nauch konf, posv pamyati prof. V.P. Yurchenko, Grodno. 2013; 24:70-72 (in Russian).

10. Abdallah M, Gashti M, McEvenue GM. Persistent sciatic artery aneurysm presenting with limb threatening ischemia: a case report and review. Vasc Dis Management. 2010;7(3): 82-85.

11. Javdanfer A, Celentano, C. Sciatic Artery Aneurysm. West J Emerg Med. 2010;11(5): 516-517.

12. Yamamoto $\mathrm{H}$, Yamamoto $\mathrm{F}$, Ishibashi $\mathrm{K}$, et al. Intermediate and long term after treating symptomatic persistent sciatic artery using different techniques. Ann Vasc Surg. 2011; 25(6): 837-852.

13. Tsyigankov VN, Varava AB. Angiography with persistent sciatic artery. Med vizualizatsiya. 2013;4:98-102 (in Russian).

14. Khmara TV, Vasylchyshyna AV. Topographic anatomic features of the accompanying vessels of the sciatic nerve in human fetuses. Klin. anatomiia ta operat. khirurhiia. 2016; 15(1):74-77 (in Ukrainian). 
15. Choi YK, Ahn JH, Kim KC, Won TH. Treatment of complete persistent sciatic artery with thromboembolism by thromboembolectomy only. Korean J Thorac Cardiovasc Surg. 2012;45:342-344.

16. Cowan MM, Hamweyah KM, Sabbagh MD, Swaid BA, Alkattan AK, Ganguly P. Persistent bilateral sciatic artery: report of a rare case. Int J Angiol. 2010;19(1):43-44.

17. Nayak BS, Kumar N, Shetty SD, Guru A. Looped external iliac artery - a case report. Int J Morphol. 2012;30(3):870-871.

18. Aristarhov EN. To the question of histotopography of the sciatic nerve. Sb. mater. II Vseros. konf. s mezhdunar. uchastiem stud. i molodyih uchenyih v ramkah «Dney molodezhnoy med. nauki», posv. 125-letiyu so dnya rozhd. chl.-korr. AMN SSSR prof. F.M. Lazarenko. Orenburg: Izd-vo OrGMA. 2013; 26-27 (in Russian).

19. Hirooka M, Iuchi H, Kurose K, Kumagi T, Horiike N, Onji $\mathrm{M}$. Abdominal virtual ultrasonographic images reconstructed by multi-detector row helical computed tomography. Eur J Radiol. 2005; 53:312-317.

20. Testoni PA, Mariani A, Mangiavillano B, et al. Main pancreatic duct, common bile duct and sphincter of Oddi structure visualized by optical coherence tomography: An ex vivo study compared with histology. Digestive and Liver Disease. 2006; 38(6):409-414.

21. Moore KL, Persaud TVN, Shiota K. Color Atlas of Clinical Embryology [2nd ed.]. Philadelphia: 2000; Elsevier Science.

22. Akhtemiichuk YuT, Tsyhykalo OV, Lisnychok SO. Methodology for studying the topographic anatomy of organocomplexes of fetuses and newborns by X-ray, contrast-induced injection of vessels and hollow organs. Suchasni problemy klinichnoi ta teoretychnoi medytsyny: nauk.-prakt. konf. (m. Sumy, 20-22 kvitnia 2005 r.): 2005; mater. konf., $42-43$ [in Ukrainian].

23. Antypkin YuH, Podolskyi VV. Newest perinatal technologies and their role in reducing the incidence of fetuses and newborns. Zdorove zhenshchynu. 2010; 5: 166-170 [in Ukrainian].

24. Akhtemiichuk YuT, Tsyhykalo OV, Livak DM. Method of three-dimensional reconstruction of microscopic anatomical structures. Problemyi, dostizheniya i perspektivyi razvitiya mediko-biologicheskih nauk i prakticheskogo zdravoohraneniya. Trudyi Kryimskogo gos. med. un-ta im. S.I. Georgievskogo. 2006; 142(1): 128 [in Ukrainian].

25. Akhtemiichuk YuT, Tsyhykalo OV. Preparation of series of digital images for three-dimensional computer reconstruction of anatomical structures. Aktualni problemy funktsionalnoi morfolohii ta intehratyvnoi antropolohii: nauk.-prakt. konf., prysv. 30-richchiu naukovo-doslidnoi laboratorii funktsionalnoi morfolohii ta henetyky rozvytku (m. Vinnytsia, 20-21 travnia 2009 r.): 2009; mater. konf., 23 [in Ukrainian].

26. Tsyhykalo OV. Method of contrasting episotopic three-dimensional reconstruction of microscopic anatomical structures. Anatomo-khirurhichni aspekty dytiachoi hastroenterolohii: 3-y Naukov. sympozium (m. Chernivtsi, 10 kvitnia 2012 r.): mater. sympoziumu. Chernivtsi: BDMU. 2012; $52-53$ [in Ukrainian].

27. Shkvarko MG, Kuzmenko AV. Variant anatomy of the branches of the upper gluteal artery. Sb. trudov nauchno-prakt. konf. „Vesennie anatomicheskie chteniya“, posv. pamyati prof. S.S. Usoeva (10-11 maya 2012 g.). Grodno: GrGMU. 2012; $135-141$ [in Russian]. 